\title{
Practice guideline: Treatment for insomnia and disrupted sleep behavior in children and adolescents with autism spectrum disorder
}

\author{
Report of the Guideline Development, Dissemination, and Implementation \\ Subcommittee of the American Academy of Neurology
}

Ashura Williams Buckley, MD, Deborah Hirtz, MD, Maryam Oskoui, MD, Melissa J. Armstrong, MD, MSc, Anshu Batra, MD, Carolyn Bridgemohan, MD, Daniel Coury, MD, Geraldine Dawson, PhD, Diane Donley, MD, Robert L. Findling, MD, MBA, Thomas Gaughan, David Gloss, MD, MPH\&TM, Gary Gronseth, MD, Riley Kessler, Shannon Merillat, MLIS, David Michelson, MD, Judith Owens, MD, MPH, Tamara Pringsheim, MD, Linmarie Sikich, MD, MA, Aubyn Stahmer, PhD, Audrey Thurm, PhD, Roberto Tuchman, MD, Zachary Warren, PhD, Amy Wetherby, PhD, Max Wiznitzer, MD, and Stephen Ashwal, MD

Neurolog ${ }^{\circledR}$ 2020;94:392-404. doi:10.1212/WNL.0000000000009033

\section{Abstract}

\section{Objective}

To review pharmacologic and nonpharmacologic strategies for treating sleep disturbances in children and adolescents with autism spectrum disorder (ASD) and to develop recommendations for addressing sleep disturbance in this population.

\section{Methods}

The guideline panel followed the American Academy of Neurology 2011 guideline development process, as amended. The systematic review included studies through December 2017. Recommendations were based on evidence, related evidence, principles of care, and inferences.

\section{Major recommendations (Level B)}

For children and adolescents with ASD and sleep disturbance, clinicians should assess for medications and coexisting conditions that could contribute to the sleep disturbance and should address identified issues. Clinicians should counsel parents regarding strategies for improved sleep habits with behavioral strategies as a first-line treatment approach for sleep disturbance either alone or in combination with pharmacologic or nutraceutical approaches. Clinicians should offer melatonin if behavioral strategies have not been helpful and contributing coexisting conditions and use of concomitant medications have been addressed, starting with a low dose. Clinicians should recommend using pharmaceutical-grade melatonin if available. Clinicians should counsel children, adolescents, and parents regarding potential adverse effects of melatonin use and the lack of long-term safety data. Clinicians should counsel that there is currently no evidence to support the routine use of weighted blankets or specialized mattress technology for improving disrupted sleep. If asked about weighted blankets, clinicians should counsel that the trial reported no serious adverse events with blanket use and that blankets could be a reasonable nonpharmacologic approach for some individuals.

\author{
Correspondence \\ American Academy of \\ Neurology \\ guidelines@aan.com
}




\section{Glossary}

AAN = American Academy of Neurology; $\mathbf{A B C}=$ Aberrant Behavior Checklist ADHD $=$ attention-deficit $/$ hyperactivity disorder; $\mathbf{A E}=$ adverse event; $\mathbf{A S D}=$ autism spectrum disorders; $\mathbf{C A M}=$ complementary and alternative medicine; $\mathbf{C B T}=$ cognitive-behavioral therapy; $\mathbf{C I}=$ confidence interval; COI = conflict of interest; CSHQ = Children's Sleep Habits Questionnaire; CSHQ-NW = CSHQ-Night Wakings; CSHQ-SD = CSHQ-Sleep Duration; CSHQ-SOD = Children's Sleep Habits Questionnaire-Sleep Onset Delay; DBC = Developmental Behavior Checklist; DSM-5 = Diagnostic and Statistical Manual of Mental Disorders, 5th edition; FDA = Food and Drug Administration; GDDI = American Academy of Neurology Guideline Development, Dissemination, and Implementation Subcommittee; GERD = gastroesophageal reflux disorder; OSA = obstructive sleep apnea; $\mathbf{O T C}=$ over-the-counter; $\mathrm{RMD}=$ raw mean difference; $\mathrm{SE}=$ sleep efficiency; $\mathrm{SOL}=$ sleep onset latency; SR = systematic review; STS = Sound-to-Sleep; TST = total sleep time; WASO = wake after sleep onset.

Autism spectrum disorders (ASD) are complex neurodevelopmental disorders characterized by social interaction/communication challenges and restrictive, stereotyped behavior patterns. Sleep disturbances in ASD are common, including difficulties initiating and maintaining sleep, frequent and prolonged night awakenings, irregular sleep-wake patterns, short sleep duration, and early-morning waking. ${ }^{1}$ Between $44 \%$ and $83 \%$ of children and adolescents with ASD report coexisting sleep abnormalities, adversely affecting daily functioning. ${ }^{2}$ Although up to $40 \%$ of typically developing children and adolescents have sleep problems, these often lessen with age. In children and adolescents with ASD, sleep problems often persist. ${ }^{3}$ Sleep disturbance severity is associated with poor physical health and quality of life. ${ }^{4}$ Poor sleep quality and insufficient nighttime sleep can exacerbate core and associated ASD features, contributing to negative effects on mood and emotional regulation, behavior, and cognitive functioning. Children and adolescents with intellectual disabilities and severe symptoms associated with ASD are at especially high risk for sleep problems. ${ }^{5-7}$ Sleep disturbances are associated with communication deficits and restrictive and repetitive behaviors in ASD. ${ }^{8,9}$ Sleep disorders negatively affect sleep and quality of life of affected individuals and their families. ${ }^{10}$ Disordered sleep is also associated with daytime behavioral disturbances, ${ }^{11-13}$ increased injury risk, ${ }^{14,15}$ obesity, ${ }^{16}$ and poor academic performance $^{17-19}$ in general pediatric populations.

Contributors to circadian rhythm misalignment potentially include dysregulated melatonin synthesis or altered melatonin secretion patterns, circadian clock gene anomalies, ${ }^{20}$ and decreased awareness of social and environmental clues that help habituate sleep-wake cycles. Abnormalities in GABAergic, glutamatergic, serotonergic, and dopaminergic systems in ASD are also possible contributors. Coexisting conditions such as epilepsy, nocturnal gastroesophageal reflux disorder (GERD), anxiety, depression, bipolar disorder, psychosis, and attentiondeficit/hyperactivity disorder (ADHD) can further contribute to sleep problems. Core or co-occurring ASD symptoms such as intellectual disability, sensory integration deficits, ritualistic or self-injurious behaviors, poor communication skills, and limited responsiveness to social cues can interfere with sleep training and exacerbate or prolong sleep problems.

Children and adolescents with ASD and sleep disturbances often receive combined medication, behavioral, and complementary and alternative medicine (CAM) treatments. Exogenous melatonin is a synthetic form of endogenous melatonin, a hormone that is the primary biomarker for circadian sleep regulation. Melatonin has chronobiologic (circadian) functions and hypnotic effects. Over-the-counter (OTC) preparations are considered supplements and not subject to US Food and Drug Administration (FDA) purity regulations. Pharmaceutical grade preparations are prescribed for exact dosing. Behavioral therapies for children aged $\leq 5$ years include unmodified, graduated extinction; positive routines; and bedtime fading. ${ }^{21}$ Older children and adolescents may respond to cognitive-behavioral therapy (CBT) adapted from adult paradigms. ${ }^{22,23}$ These interventions are short-term, multicomponent, goal-oriented psychotherapeutic treatments aiming to modify thinking patterns and behaviors that perpetuate insomnia (e.g., irregular sleep-wake schedules, poor sleep hygiene, and maladaptive habits).

This guideline addresses the following question:

In children and adolescents with ASD, which pharmacologic, behavioral, and CAM interventions improve (1) bedtime resistance, (2) sleep onset latency (SOL), (3) sleep continuity, (4) total sleep time (TST), and (5) daytime behavior?

\section{Description of the analytic process}

This guideline follows the 2011 American Academy of Neurology (AAN) guideline development process manual, as amended. ${ }^{24}$ The AAN Guideline Development, Dissemination, and Implementation Subcommittee (GDDI) approved initiation of autism treatment guidelines in 2012 (appendices e-1 and e-2; see full-length guideline at aan.com/Guidelines/ home/GetGuidelineContent/1004 for appendices). Panel leadership reviewed conflict of interest (COI) forms and curriculum vitae of potential panel members, according to AAN COI policy. ${ }^{24}$ The GDDI approved formation of 
a multidisciplinary panel including child neurologists, psychiatrists, neuropsychologists, and developmental pediatricians. Evidence-based medicine methodologists supported the project. Six of the 26 authors had COIs that were not significant enough to preclude participation. Restrictions on their roles reflect AAN policy. ${ }^{24}$ The lead author had no COIs.

Studies used various strategies for defining ASD, particularly because some were conducted before the publication of the DSM-5. ${ }^{25}$ This guideline uses the most recently established and inclusive term: ASD. Readers should consult source publications for details regarding studies' diagnostic approaches.

The initial plan was to use previously published systematic reviews (SRs). However, identified reviews contained insufficient information for assessing the level of evidence of individual studies. The guideline panel thus rated studies included in each SR using standard AAN methodology. Panelists evaluated 900 abstracts of articles from SRs for inclusion. A medical research librarian performed updated literature searches (June 24, 2016, and December 21, 2017; comprehensive search strategy in appendix e-3, aan.com/Guidelines/home/GetGuidelineContent/1004), retrieving 1,087 additional abstracts. Of 1,987 abstracts, 139 were potentially relevant. Twelve articles met criteria for data extraction. Eight were rated Class III or higher and were included in the review (figure). Classification of evidence, evidence synthesis, and recommendation development followed AAN methodology. ${ }^{24}$ The panel based practice recommendations on the evidence strength, axiomatic principles, strong related evidence, and inferences. Level of obligation was assigned through modified Delphi voting. ${ }^{24}$

There are no established clinically important differences for study outcomes. Panelists were surveyed to achieve consensus regarding clinically important and unimportant differences (e.g., for actigraphy) (table e-1; see full-length guideline for e-tables, aan.com/Guidelines/home/GetGuidelineContent/ 1004). Three questionnaires were used in included studies: the Children's Sleep Habits Questionnaire (CSHQ; 45 items, each graded 1-3), ${ }^{26}$ the Developmental Behavior Checklist (DBC; 96 items, each graded 0-2), ${ }^{27}$ and the Aberrant Behavior Checklist (ABC; 58 items, each graded $0-3) .{ }^{28}$ Higher scores indicate greater symptom burden. A change of $<1 \%$ was considered unimportant and a change of $>10 \%$ was considered important when assessing questionnaire scores.

\section{Analysis of evidence}

All trials occurred in the United States or Europe and included children and adolescents with ASD and aged $\leq 18$ years.

\section{Bedtime resistance}

Bedtime resistance is a behavioral phenomenon manifesting as refusing to go to bed, stalling, or requiring a parent's presence at sleep onset. One Class II study examined the use of melatonin and family-based CBT. ${ }^{29}$ No other studies were identified.

\section{Melatonin and CBT}

The Class II study was placebo-controlled and had 4 primary outcomes. ${ }^{29}$ Children (4-10 years old) with ASD and sleep onset insomnia or maintenance insomnia or both were randomized to one of 4 arms: $3 \mathrm{mg}$ of prolonged-release melatonin, taken at $9 \mathrm{PM}(\mathrm{n}=34) ; 4$ weekly 50-minute sessions of family-based CBT followed by twice-monthly maintenance sessions $(\mathrm{n}=33)$; melatonin plus CBT $(\mathrm{n}=$ $35)$; or placebo $(n=32) \cdot{ }^{30}$ The high-purity melatonin (99.9\%) released $1 \mathrm{mg}$ immediately and $2 \mathrm{mg}$ over 6 hours. Bedtime resistance was measured with the CSHQ-Bedtime Resistance subscale (6-18 points). ${ }^{26}$ Baseline and 12 -week scores were reported, but information was insufficient to calculate mean change differences between groups with confidence intervals (CIs). Bedtime resistance scores were lower for children in each active treatment group vs placebo (raw mean difference [RMD] in 12-week scores vs placebo: combination therapy -5.64 [95\% CI, -6.45 to -4.83$]$; melatonin -3.60 [95\% CI, -4.60 to -2.60 ]; CBT -2.48 [95\% CI, -3.49 to -1.47$])$. Melatonin was well-tolerated. No adverse events (AEs) were reported.

\section{Sleep onset latency}

SOL refers to the amount of time from lights turned off until the onset of any sleep stage.

\section{Melatonin and CBT}

One Class I study and 2 Class II studies were identified. In the Class I study, 125 children (2-17.5 years old) with ASD, sleep problems for $\geq 3$ months, and no response to 4 weeks of behavioral therapy were randomized to prolonged-release melatonin $2-5 \mathrm{mg} / \mathrm{d}$ (titration up to $10 \mathrm{mg} / \mathrm{d}$ ) or placebo after a 2 -week, single-blind placebo run-in. ${ }^{31}$ At 13 weeks, children receiving melatonin had a larger mean decrease in diary-reported SOL compared with those receiving placebo ( -25.3 minutes; $95 \% \mathrm{CI},-44.7$ to -5.9 ).

In the previously described Class II study, ${ }^{29}$ SOL was measured by actigraphy and the CSHQ-Sleep Onset Delay (CSHQSOD) subscale (1-3 points). ${ }^{26}$ Children receiving prolongedrelease melatonin with family-based CBT had the lowest SOL at 12 weeks vs placebo (RMD: actigraphy -45.91 minutes [95\% CI, -57.93 to -33.89 ], CSHQ-SOD: -1.24 [95\% CI, -1.50 to -0.98$]$ ). Prolonged-release melatonin and CBT individually also resulted in lower 12-week SOL vs placebo (melatonin: actigraphy -34.39 minutes [95\% CI, -47.91 to -20.88], CSHQ-SOD: -0.83 [95\% CI, -1.07 to -0.59 ]; CBT: actigraphy -20.47 minutes [ $95 \% \mathrm{CI},-34.98$ to -5.96 ], CSHQSOD -0.42 [95\% CI, -0.63 to -0.21$]$ ).

A Class II (3 primary outcomes) crossover study using standard-release melatonin (up to $10 \mathrm{mg} / \mathrm{d}$; modal dose 7 $\mathrm{mg}$ ) for 12 weeks in children (3-16 years old) with ASD and sleeplessness $(n=17)$ measured SOL using sleep diaries. ${ }^{32}$ Participants had excessive sleep latencies (>30 minutes) and an unsuccessful behavioral management trial. The RMD for SOL reduction between weeks receiving melatonin vs placebo 


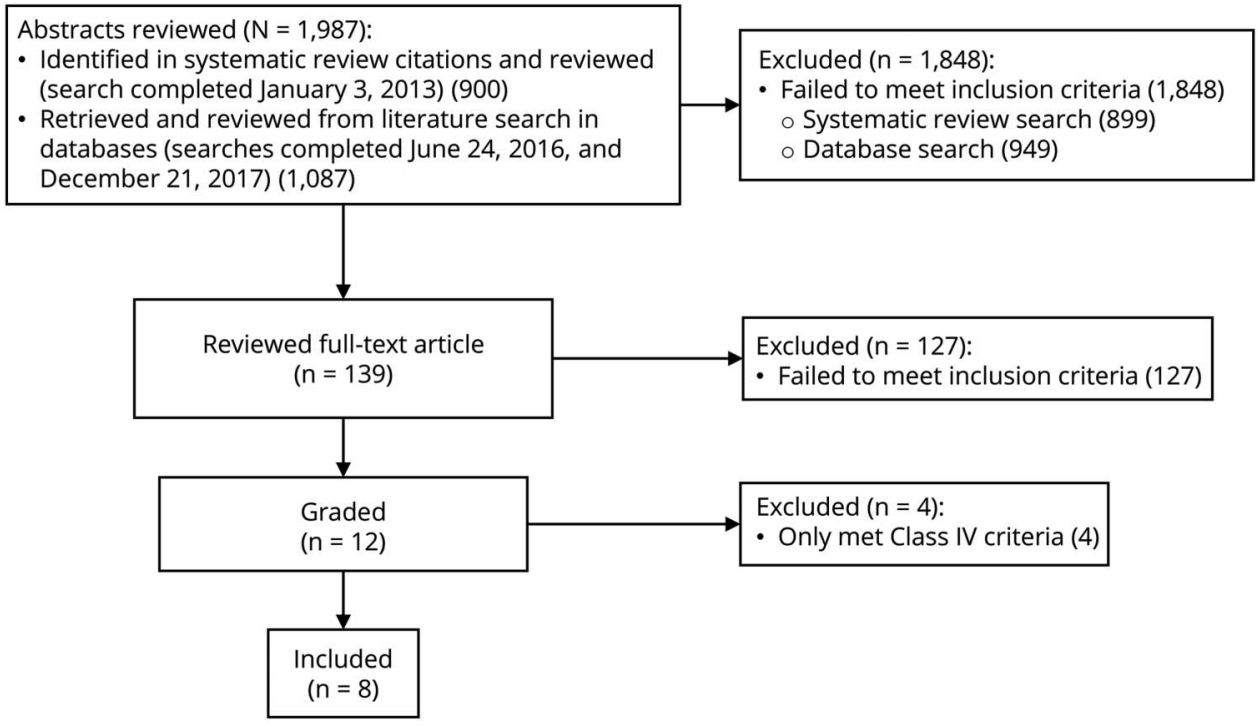

was -46.7 minutes ( $95 \% \mathrm{CI},-78.50$ to -14.90 ). Melatonin was well-tolerated. No AEs were reported.

A random-effects meta-analysis was performed combining results from all 3 studies with the assumptions that (1) prolonged-release and standard melatonin forms were substantively similar, (2) SOL measurements from actigraphy vs diaries were similar, and (3) RMDs in 12-week SOL scores ${ }^{29}$ were similar to differences in mean change in $\mathrm{SOL}^{31,32}$ given similar baseline SOL in melatonin and placebo groups. This meta-analysis resulted in an estimated mean reduction in SOL of -33.1 minutes (95\% CI, -43.5 to $-22.6 ; I^{2}=0 \%$ ) for children with ASD and sleep disturbance treated with melatonin.

\section{Parent-based sleep education}

Two Class II studies ${ }^{33,34}$ and 1 Class III study ${ }^{35}$ used parental $^{3}$ education about sleep schedules and hygiene. In one study (Class II for actigraphy outcomes), children (2-10 years old) with ASD and a mean SOL of $\geq 30$ minutes were randomized to have a parent receive a 4-page educational pamphlet $(n=19)$ or nothing $(\mathrm{n}=17) .{ }^{33}$ The pamphlet described providing a comfortable sleep setting, establishing regular bedtime habits, keeping a regular schedule, teaching one's child to fall asleep alone, avoiding naps, and encouraging daytime activities promoting better sleep-wake schedules. There was no difference in SOL between children whose parents received the pamphlet and those whose parents received no instruction (RMD in SOL at 2 weeks: -11.8 minutes; $95 \% \mathrm{CI},-37.16$ to 13.56 ; difference in mean change between baseline and 2 weeks: -16.4 minutes; $95 \%$ CI, -39.3 to 6.5$)$.

A Class II study investigated the effect of parental sleep education for children (2-10 years old) with ASD and SOL of $\geq 30$ minutes at least 3 nights weekly. ${ }^{34}$ This study was Class
IV for the full cohort (no comparison group) but Class II for comparing actigraphy outcomes after individual vs group education. Children whose parents received individual training were not more likely to have lower SOL at 4 weeks after intervention than those whose parents received group training (RMD: -0.2 minutes; $95 \% \mathrm{CI},-9.79$ to 9.39 ).

In a Class III placebo-controlled study ( $>20 \%$ lost for actigraphy outcomes, 4 primary outcomes, no allocation concealment) in children with ASD and at least 1 sleep disturbance (average age 3.5 years), parents were randomized to receive either sleepspecific behavioral training $(n=20)$ or non-sleep-related education $(n=20) .{ }^{35}$ Both arms received 5 sessions over 8 weeks. Sleep changes were measured by actigraphy $(n=27)$. Baseline, 4-week, and 8-week scores were reported, but information was insufficient for calculating mean change differences between groups with CIs. Baseline SOL was shorter in the control group (29 minutes, SD 27) than the behavioral training group (35 minutes, SD 31). Children whose parents received sleepfocused education were not more likely to have shorter SOL at 8 weeks than those whose parents received non-sleep-related education (RMD: 4.0 minutes; $95 \% \mathrm{CI},-14.24$ to 22.24 ).

\section{Weighted blankets}

A 2-week crossover trial in children (5-16 years old) with ASD was Class II for actigraphy outcomes (74\% of randomized participants included in analysis) and Class III for sleep diary outcomes. ${ }^{36}$ Children had a $\geq 5$-month history of sleep complaints in the absence of obstructive sleep apnea (OSA), night terrors, or other sleep disorders $(n=54-67$, depending on arm). SOL was no shorter during weeks weighted blankets were used than during weeks regular blankets were used (mean change difference: actigraphy: 2.1 minutes; $95 \% \mathrm{CI},-5.30$ to 9.50; sleep diary: -1.6 minutes; $95 \% \mathrm{CI},-6.61$ to 3.41 ). 


\section{Sound-to-Sleep (STS) mattress technology}

One randomized crossover trial investigated the use of STS mattress technology in 45 children $(2.5-12.9$ years old) with ASD and significant sleep difficulties (CSHQ score $\geq 41$ ). ${ }^{37}$ The STS mattress embeds vibrations corresponding to a chosen sound source into the mattress. The study was Class II for actigraphy and Class III for diary results. There were no baseline actigraphy data. No difference was seen in 2-week SOL between the off (18.2 minutes) and on (14.11 minutes) condition as measured by actigraphy in the 38 children completing the study (RMD: -4.09 minutes; $95 \% \mathrm{CI},-11.2$ to 3.0 ).

\section{Sleep continuity: sleep efficiency (SE)}

Sleep continuity is the amount of consolidated sleep attained over a sleep period. Continuity is reported using SE, TST, wake after sleep onset (WASO), and number of nighttime awakenings. SE is the percentage of time spent asleep while in bed (including time in bed while falling asleep and time between waking and arising from bed).

\section{Melatonin and CBT}

In a previously described Class II study, mean actigraphy SE scores at 12 weeks were higher in children receiving prolongedrelease melatonin plus family-based CBT (RMD: 12.53\%; 95\% CI, 10.40-14.66), prolonged-release melatonin (RMD: 10.78\%; 95\% CI, 8.69-12.87), and CBT (RMD: 7.65\%; 95\% CI, 5.78-9.52) vs placebo.

\section{Parent-based sleep education}

In the Class II educational pamphlet study, children whose parents received the pamphlet had greater improvement in actigraphy-measured SE at 12 weeks compared with those whose parents received no instruction (mean change $+2.3 \%$ vs $-1.7 \%$; difference in mean change $4.0 \%$; $95 \%$ CI, $0.18-7.82$ ). However, the children did not have a statistically higher SE at 12 weeks ( $77.8 \% \pm 7.0 \%$ vs $75.1 \% \pm 6.7 \%$; RMD: $2.70 \%$; $95 \%$ CI, -1.78 to 7.18$).^{33}$ The Class II study comparing individual with group parent sleep education found no difference in actigraphy-measured SE at 4 weeks between children whose parents were in individual vs group sessions $(78.7 \%$ vs $79.8 \%$; RMD: $-1.10 \%$; $95 \%$ CI, -3.61 to 1.41$).{ }^{34}$ In the Class III study comparing sleep-specific behavioral training with control parental education over 8 weeks, baseline SE was $>80 \%$ in both groups. Actigraphy-measured SE was similar between groups at 8 weeks (SE $85 \% \pm 6 \%$ in children whose parents received sleep-specific training vs $86 \% \pm 10 \%$ in children whose parents received non-sleep-based education; RMD: $-1.0 \%$; 95\% CI, -7.17 to 5.17$)$. $^{35}$

\section{Weighted blankets}

In a previously described Class II trial, SE was not different during weeks of weighted blanket use than during weeks of regular blanket use (RMD: $-0.3 \%$; $95 \% \mathrm{CI}-1.41$ to 0.81 ). ${ }^{36}$

\section{STS mattress technology}

In the STS mattress technology study (Class II for actigraphy), children had higher SE over 2 weeks of using the STS system turned on (78.27\%) compared with 2 weeks with the technology off (75.45\%) (RMD: 2.82\%; 95\% CI, 1.14-4.50). ${ }^{37}$

\section{Sleep continuity: night awakenings}

WASO describes the time individuals spend awake after sleep onset and before sleep offset. Night awakenings reference the number of complete awakenings occurring after sleep initiation.

\section{Melatonin and CBT}

In a previously described Class I study, children receiving prolonged-release melatonin had no difference in the duration of wake time ( -0.08 minutes; $95 \% \mathrm{CI},-7.02$ to 6.86$)$ or number of awakenings $(-0.09 ; 95 \% \mathrm{CI},-0.35$ to 0.16$)$ at 13 weeks vs children receiving placebo. ${ }^{31}$ The Class II study including melatonin and family-based $\mathrm{CBT}$ used actigraphy to measure WASO and the CSHQ-Night Wakings (CSHQ-NW) subscale to measure night awakenings. ${ }^{29}$ Children in the combined therapy group had the largest difference in WASO at 12 weeks vs placebo (RMD: -40.46 ; $95 \% \mathrm{CI},-55.89$ to -25.03). Children in the melatonin-only group also had lower WASO vs the placebo group (RMD: -27.94 minutes; 95\% CI, -44.55 to -11.33 ). No difference in WASO was seen for CBT alone vs placebo (RMD: -8.98 minutes; $95 \% \mathrm{CI},-26.78$ to 8.82). On the CSHQ-NW (range 3-9), children in all 3 treatment groups had lower 12-week scores than children in the placebo group (RMD for combination group: $-3.44 ; 95 \% \mathrm{CI}$, -3.85 to -3.03 ; melatonin-only group: -2.83 ; $95 \% \mathrm{CI},-3.29$ to -2.37 ; CBT-only group: -0.80 ; $95 \% \mathrm{CI},-1.26$ to -0.34 ). In the Class II crossover study using melatonin $2-10 \mathrm{mg} / \mathrm{d}$, there was no difference in the number of diary-reported night awakenings after weeks participants received melatonin vs weeks they received placebo (RMD: $-0.1 ; 95 \% \mathrm{CI},-0.26$ to -0.06 ). ${ }^{32}$

Random-effects meta-analyses used the prior assumptions. There was no difference between melatonin and placebo for WASO ( -12.95 minutes; $95 \% \mathrm{CI},-40.17$ to 14.28 ; $\left.I^{2}=89 \%\right)^{29,32,36}$ and number of awakenings $(-0.097 ; 95 \%$ CI, -2.33 to $\left.0.038 ; I^{2}=0 \%\right) .{ }^{32,36}$

\section{Parent-based sleep education}

In the Class II educational pamphlet study, there was no difference in actigraphy-measured WASO when parents received the pamphlet vs when parents did not (RMD in scores at 2 weeks: 0.5 minutes; $95 \% \mathrm{CI},-17.96$ to 18.96 ; difference in mean change: -8.2 minutes; $95 \% \mathrm{CI},-21.30$ to 4.90$).{ }^{33}$ In the Class II study comparing individual and group sleep education, there was no difference in actigraphy-measured WASO when parents received individual sessions vs group sessions (RMD at 4 weeks: 1.00 minutes; $95 \% \mathrm{CI},-10.24$ to 12.24 ; difference in mean change: -2.4 minutes; $95 \% \mathrm{CI},-7.65$ to 2.85$){ }^{34}$

\section{Weighted blankets}

In the weighted blanket crossover study (Class II for actigraphy, Class III for diary outcomes), sleep discontinuity was measured 4 ways: (1) number of times children awoke (actigraphy), (2) actigraphy-measured WASO, (3) proportion of nights weekly that children awoke (sleep diary), and (4) average WASO 
(sleep diary). ${ }^{36}$ There was no difference in actigraphy-measured WASO (RMD: -2.5 minutes; 95\% CI, -9.49 to 4.49 ) or awakenings (RMD: -0.2 ; 95\% CI, -1.05 to 0.65 ) between weeks of weighted blanket use vs weeks of control blanket use. Sleep diaries showed no difference in the proportion of nights with at least 1 awakening (RMD: $-0.01 ; 95 \% \mathrm{CI},-0.05$ to 0.03 ) or average time awake (RMD: 0.01 minutes; $95 \% \mathrm{CI},-1.41$ to 1.43) between conditions.

\section{STS mattress technology}

In the STS mattress technology crossover trial, WASO was not different when measured by actigraphy over 2 weeks (18.79 minutes with technology off, 17.85 minutes with technology on; RMD: -0.94 minutes; $95 \% \mathrm{CI},-1.912$ to 0.032 ) or sleep diary (off: 0.13 minutes, on: 0.12 minutes; RMD: -0.01 minutes; $95 \% \mathrm{CI},-0.043$ to 0.023$).{ }^{37}$

\section{Total sleep time}

TST refers to sleep duration during a given sleep period time (usually at night). Reduced TST relates to prolonged SOL, night awakenings, and early-morning waking. Included studies compare TST changes with treatment rather than referencing age-specific sleep duration recommendations.

\section{Melatonin and CBT}

In the Class I study, children receiving prolonged-release melatonin had a greater increase in diary-reported TST (baseline to 13 weeks, 32.43 minutes; 95\% CI, 2.48-62.38). ${ }^{31}$ In the Class II study using melatonin and family-based CBT, actigraphy-measured TST at 12 weeks was longer in treatment groups compared with placebo (combined therapy group: RMD: 88.78 minutes; 95\% CI, 70.30-107.26; melatonin-only group: RMD: 64.87 minutes; 95\% CI, 46.10-83.64; CBT-only group: RMD: 28.90; 95\% CI, 6.53-51.27). ${ }^{29}$ CSHQ-Sleep Duration (CSHQ-SD) subscale outcomes (score range 3-9) at 12 weeks in the melatonin groups revealed the same pattern vs placebo (combined therapy group: RMD: -2.02 ; $95 \% \mathrm{CI}$, -2.58 to -1.46 ; melatonin-only group: $\mathrm{RMD}:-1.58$; $95 \% \mathrm{CI}$, -2.13 to -1.03$)$. There was no difference on the CSHQ-SD between the CBT-only and placebo groups (RMD: 0.28; 95\% CI, -0.32 to 0.88$)$. In the Class II crossover study, diary-based TST improved more during weeks children and adolescents received melatonin than during weeks they received placebo (RMD: 52.3 minutes; 95\% CI, 19.3-5.47). ${ }^{32}$ A random-effects meta-analysis resulted in an estimated increased TST of 52.63 minutes (95\% CI, 33.10-72.16; $I^{2}=39 \%$ ) for children with ASD and sleep disturbance treated with melatonin vs placebo.

\section{Parent-based sleep education}

Actigraphy-measured TST did not differ between children whose parents received the educational pamphlet vs no instruction (Class II study; RMD in TST at 2 weeks: 12.2 minutes; $95 \% \mathrm{CI},-22.6$ to 47.0 ; difference in mean change between baseline and 2 weeks: 7.9 minutes; $95 \% \mathrm{CI},-18.03$ to 33.8). ${ }^{33}$ Change in actigraphy-measured TST also did not differ between baseline and 4 weeks for children whose parents received individual vs group instruction (Class II study; RMD at
4 weeks: -7.2 minutes; $95 \% \mathrm{CI},-29.44$ to 15.04 ; difference in mean change: -11.7 minutes; $95 \% \mathrm{CI},-37.3$ to 13.9$).{ }^{34}$ In the Class III placebo-controlled study comparing sleep-specific behavioral training vs control education, actigraphy-measured TST at 8 weeks was not significantly different between children whose parents attended sleep education sessions and the control group (RMD: 26.0 minutes; 95\% CI, -31.33 to $83.33) .{ }^{35}$

\section{Weighted blankets}

In the weighted blanket study (Class II for actigraphy, Class III for diary outcomes), there was no difference in actigraphymeasured TST during weeks of weighted blanket use vs weeks of regular blanket use (RMD weighted control: -4.2 minutes; 95\% CI, -13.40 to 5.00$).{ }^{36}$ Diary-based TST also did not differ (RMD weighted control: 15.9 minutes; 95\% CI, -6.37 to 38.17).

\section{STS mattress technology}

In the STS mattress technology trial (Class II for actigraphy, Class III for diary results), actigraphy-measured TST was longer during the 2 weeks that the STS technology was on vs the 2 weeks it was off (on: 8.35 hours, off: 7.99 hours; RMD: 0.36 hours; 95\% CI, 0.15-0.57). ${ }^{37}$ There was no difference in diary-based TST (on: 9.78 hours, off: 9.66 hours; RMD: 0.12 hours; $95 \% \mathrm{CI},-0.18$ to 0.42 ).

\section{Daytime behavior}

\section{Melatonin}

In the Class II crossover study using melatonin $2-10 \mathrm{mg} / \mathrm{d}$ vs placebo, total DBC scores were lower after weeks of melatonin use vs weeks of placebo use (RMD: $-6.0 ; 95 \% \mathrm{CI},-12.0$ to 0 ). The only statistically significant difference in subscale scores was for communication (RMD: -1.6 ; $95 \% \mathrm{CI},-3.16$ to 0.04 ). ${ }^{32}$

\section{Weighted blankets}

In the Class II weighted blanket trial, total $A B C$ score did not differ between periods of weighted blanket use vs periods of regular blanket use $(-2.3 ; 95 \% \mathrm{CI},-5.75$ to 1.15$)$. There were also no differences on subscale scores. ${ }^{36}$

\section{STS mattress technology}

In the STS mattress technology crossover trial (Class III for questionnaire results), $\mathrm{ABC}$ scores did not differ at the end of the 2-week off-technology and on-technology periods (RMD: -6.8 ; $95 \% \mathrm{CI},-14.8$ to 1.3$).^{37}$

\section{Conclusions (evidence synthesis)}

Various forms of melatonin with or without CBT improve multiple sleep outcomes compared with placebo (table 1 and table e-3, aan.com/Guidelines/home/GetGuidelineContent/1004). Evidence for other interventions is largely lacking. It is possible that a parental educational pamphlet, individual vs group parental sleep education, weighted blankets, and STS mattress technology have no benefits for 
Table 1 Evidence summary for interventions targeting sleep disorders in children and adolescents with autism spectrum disorder (ASD) $)^{a}$

\begin{tabular}{|c|c|c|c|c|c|c|}
\hline & $\begin{array}{l}\text { Bedtime } \\
\text { resistance }\end{array}$ & Sleep onset latency & $\begin{array}{l}\text { Sleep } \\
\text { continuity: } \\
\text { sleep } \\
\text { efficiency }\end{array}$ & $\begin{array}{l}\text { Sleep continuity: WASO, } \\
\text { night awakenings }\end{array}$ & Total sleep time & $\begin{array}{l}\text { Daytime } \\
\text { behavior }\end{array}$ \\
\hline $\begin{array}{l}\text { Probably } \\
\text { effective }\end{array}$ & $\begin{array}{l}\text { Melatonin } \\
\text { plus CBT; } \\
\text { melatonin } \\
\text { alone }\end{array}$ & $\begin{array}{l}\text { Melatonin plus CBT; } \\
\text { melatonin alone }\end{array}$ & $\begin{array}{l}\text { Melatonin plus } \\
\text { CBT; melatonin } \\
\text { alone }\end{array}$ & $\begin{array}{l}\text { Melatonin plus CBT; } \\
\text { melatonin alone }{ }^{\mathrm{b}}\end{array}$ & $\begin{array}{l}\text { Melatonin plus CBT; } \\
\text { melatonin alone }\end{array}$ & \\
\hline $\begin{array}{l}\text { Possibly } \\
\text { effective }\end{array}$ & CBT alone & CBT alone ${ }^{\mathrm{b}}$ & $\begin{array}{l}\text { CBT alone }{ }^{\text {b; }} \\
\text { parent } \\
\text { educational } \\
\text { pamphlet }^{\text {b }} \text { STS } \\
\text { mattress } \\
\text { technology }\end{array}$ & CBT alone ${ }^{b}$ & CBT alone ${ }^{b}$ & \\
\hline $\begin{array}{l}\text { Possibly } \\
\text { ineffective }\end{array}$ & & $\begin{array}{l}\text { Parent educational packet; } \\
\text { individual (vs group) } \\
\text { parent education; } \\
\text { weighted blankets; STS } \\
\text { mattress technology }\end{array}$ & $\begin{array}{l}\text { Individual (vs } \\
\text { group) parent } \\
\text { education; } \\
\text { weighted } \\
\text { blankets }\end{array}$ & $\begin{array}{l}\text { Parent educational packet; } \\
\text { individual (vs group) } \\
\text { parent education; } \\
\text { weighted blankets; STS } \\
\text { mattress technology }\end{array}$ & $\begin{array}{l}\text { Parent educational } \\
\text { pamphlet; individual (vs } \\
\text { group) parent education; } \\
\text { weighted blankets; STS } \\
\text { mattress technology }\end{array}$ & $\begin{array}{l}\text { Melatonin } \\
\text { CR; } \\
\text { weighted } \\
\text { blankets }\end{array}$ \\
\hline $\begin{array}{l}\text { Insufficient } \\
\text { evidence }\end{array}$ & & $\begin{array}{l}\text { Parental sleep-specific } \\
\text { behavioral training }\end{array}$ & $\begin{array}{l}\text { Parental sleep- } \\
\text { specific } \\
\text { behavioral } \\
\text { training }\end{array}$ & & $\begin{array}{l}\text { Parental sleep-specific } \\
\text { behavioral training }\end{array}$ & $\begin{array}{l}\text { STS } \\
\text { mattress } \\
\text { technology }\end{array}$ \\
\hline
\end{tabular}

Abbreviations: CBT = cognitive behavioral therapy; CR = controlled release; STS = Sound-to-Sleep; WASO = wake after sleep onset.

a Specific conclusion details regarding the interventions (e.g., type of melatonin, dose), outcomes measured, and timing are available in the systematic review text and the full conclusions outlined in appendix e-4 (aan.com/Guidelines/home/GetGuidelineContent/1004) of the full-length guideline, available from the American Academy of Neurology, upon request; for interventions for which there are multiple conclusions for a single sleep category, conclusions with the highest degree of confidence and potential benefit are reflected here.

${ }^{\mathrm{b}}$ Other outcomes for this intervention and this sleep category show either no benefit or have insufficient evidence.

sleep outcomes (outcomes vary slightly by intervention; table e-3, aan.com/Guidelines/home/GetGuidelineContent/1004). Evidence is insufficient to determine the effect of parental sleep-specific behavioral training on the basis of 1 Class III study. ${ }^{35}$ Evidence profile tables (appendix e-4, aan.com/Guidelines/home/GetGuidelineContent/1004) and evidence synthesis tables (appendix e-5, aan.com/Guidelines/ home/GetGuidelineContent/1004) are available from the AAN, by request.

\section{Putting the evidence into clinical context}

Treatment of sleep disorders in ASD is an important goal, as sleep disruption is associated with behavioral problems, daytime sleepiness, and poorer health. ${ }^{38}$ Individuals with ASD are at risk for primary sleep disorders, including OSA, restless legs syndrome, and periodic limb movement disorder (not reviewed). ${ }^{2,39}$ They are also at risk for sleep disorders secondary to coexisting conditions (e.g., epilepsy, GERD, anxiety, depression, bipolar disorder, psychosis, or $\mathrm{ADHD}$ ), and are more likely to use medications that disrupt normal sleep patterns (e.g., antiseizure medicines, psychotropic medications). A practice pathway for identifying, evaluating, and managing insomnia in children and adolescents with ASD emphasized the importance of identifying and treating coexisting conditions. ${ }^{40}$ Learned maladaptive sleep patterns, including lack of parental boundaries regarding sleep, may be more difficult to correct in children and adolescents with ASD than in their typically developing peers. For this reason, behavioral strategies might augment and outlast short-term pharmacologic interventions.

This review reveals a dearth of evidence-based treatments for sleep dysregulation in ASD. No identified studies examined pharmacologic approaches (e.g., antidepressants, $\alpha$-adrenergic agonists, benzodiazepines, antiseizure medicines, or antipsychotics), and the identified literature could not inform what population might be most likely to respond to treatment (e.g., based on age or comorbid symptoms). The best studies examined pharmacologic treatment with melatonin and used study-specific formulations to overcome limitations of unknown purity in OTC formulations. No medications for insomnia are FDA-approved for pediatric use. Melatonin is the most commonly dispensed hypnotic drug in children. ${ }^{41}$ However, melatonin concentrations in OTC formulations differ, and some formulations are contaminated with other products (e.g., serotonin). ${ }^{42,43}$ In 2014, the European Consensus Conference published consensus guidelines acknowledging that pediatric melatonin safety/tolerability trials are limited but there is no evidence that short-term melatonin use has serious AEs. ${ }^{44}$ The most frequently reported AEs are morning drowsiness, increased enuresis, headache, dizziness, diarrhea, rash, and hypothermia. ${ }^{45-47}$ Given that many children with ASD use melatonin for months or years, the lack of long-term safety data is concerning. Melatonin affects the hypothalamic-gonadal axis and can potentially influence pubertal development. ${ }^{48}$ 


\section{Practice recommendations}

Recommendation rationales are presented and tables 2-4 summarize recommendation statements (n.neurology.org/ content/91/10/450). Rationale profile tables are available online (appendix e-6, aan.com/Guidelines/home/GetGuidelineContent/1004).

\section{Recommendation 1 rationale: addressing coexisting medical conditions and concomitant medications}

Children and adolescents with ASD are at increased risk of cooccurring conditions that contribute to sleep disturbance, such as intellectual disability, sleep apnea, epilepsy, gastrointestinal disturbances (including GERD), depression, anxiety, psychosis, bipolar disorder, and ADHD. Children and adolescents with ASD are also more likely to use medications that disrupt normal sleep patterns, such as stimulants, some antiseizure medicines, and psychotropic medications.

\section{Recommendation 2 rationale: behavioral strategies}

Environment and family factors, including child-rearing practices and bedtime routines that are not conducive to good sleep, contribute to sleep disturbance in children with ASD. ${ }^{49}$ Although robust evidence for parental education and behavioral strategies to improve sleep in children and adolescents with ASD is lacking, suggested approaches include the following:

- Unmodified extinction: parents impose a set bedtime and wake-up time and ignore protest behavior that occurs after the bedtime and before the wake-up time

- Graduated extinction: parents ignore bedtime resistance for specified periods that are fixed or get progressively longer and then respond without reinforcing the resistant behavior (i.e., brief and boring verbal reassurance)

- Positive routines: parents develop and strictly adhere to regular pre-bed calming rituals

- Bedtime fading: parents put their child to bed close to the time the child begins to fall asleep ${ }^{21}$

In addition, this SR has shown that family-based CBT with or without melatonin may improve several aspects of sleep. In the study, families attended 4 weekly 50-minute sessions of CBT, where parents/caregivers received education and instruction on how to modify behavior regarding sleep and were required to complete homework practicing strategies and then twicemonthly maintenance sessions over the 12 study weeks. ${ }^{29}$ As a general tenet of pediatric practice, behavioral strategies are the preferred first treatment option before initiation of pharmacologic approaches. Successful application of behavioral approaches will require knowledgeable clinicians who can teach parents appropriate techniques and that parents implement the techniques consistently despite discomforts and challenges associated with behavioral modification.

\section{Recommendation 3 rationale: melatonin}

When managing coexisting conditions and adopting behavioral strategies are unsuccessful at improving sleep of children and adolescents with ASD, pharmacologic strategies are an additional treatment approach. There is low to moderate confidence that melatonin improves various aspects of sleep in children and adolescents with ASD. In the studies included in the SR, pharmaceutical-grade melatonin preparations were used and the exact administration amounts ascertained. One study used prolonged-release melatonin up to $10 \mathrm{mg} / \mathrm{d},{ }^{32}$ one used $3 \mathrm{mg}$ of prolonged-release melatonin, ${ }^{29}$ and one started $2 \mathrm{mg}$ of immediate-release melatonin with titration to effect

Table 2 Recommendation statements ${ }^{a}$ for care of children and adolescents with autism spectrum disorder (ASD) and sleep disturbance regarding coexisting medical conditions and concomitant medications

\begin{tabular}{|c|c|}
\hline $\begin{array}{l}\text { Recommendation } \\
\text { number }\end{array}$ & Recommendation statement and level \\
\hline $1 a$ & $\begin{array}{l}\text { Clinicians seeking to improve sleep in children and adolescents with ASD should perform an assessment for coexisting conditions } \\
\text { that could be contributing to sleep disturbance (Level B). }\end{array}$ \\
\hline $1 b$ & $\begin{array}{l}\text { Clinicians seeking to improve sleep in children and adolescents with ASD should review concomitant medications that could be } \\
\text { contributing to sleep disturbance (Level B). }\end{array}$ \\
\hline $1 c$ & $\begin{array}{l}\text { Clinicians seeking to improve sleep in children and adolescents with ASD who have a coexisting condition that is contributing to } \\
\text { their sleep disturbance should ensure they receive appropriate treatment for their coexisting condition (Level B). }{ }^{\mathrm{b}}\end{array}$ \\
\hline $1 d$ & $\begin{array}{l}\text { Clinicians seeking to improve sleep in children and adolescents with ASD who have medications that could be contributing to } \\
\text { sleep disturbance should address whether the potentially contributing medications can be stopped or adjusted (Level B). }\end{array}$ \\
\hline 2 & $\begin{array}{l}\text { Clinicians seeking to improve sleep function in children and adolescents with ASD should counsel parents or guardians regarding } \\
\text { strategies for improved sleep habits, with behavioral strategies as a first-line treatment approach either alone or in combination } \\
\text { with pharmacologic or nutraceutical approaches, depending on individual circumstances (Level B). }\end{array}$ \\
\hline \multicolumn{2}{|c|}{$\begin{array}{l}\text { a Level A is the strongest recommendation level and is denoted by use of the helping verb must. These recommendations are rare. Level B corresponds to the } \\
\text { helping verb should. Such recommendations are more common, as the requirements are less stringent but are still associated with confidence in the } \\
\text { rationale and a favorable benefit-risk profile. Level C corresponds to the helping verb may. These recommendations represent the lowest allowable } \\
\text { recommendation level that the American Academy of Neurology considers useful within the scope of clinical practice and can accommodate the highest } \\
\text { degree of practice variation. } \\
\text { b Level B based on feasibility and cost relative to net benefit. }\end{array}$} \\
\hline
\end{tabular}


Table 3 Recommendation statements for care of children and adolescents with autism spectrum disorder (ASD) and sleep disturbance regarding melatonin use

\begin{tabular}{ll}
\hline $\begin{array}{l}\text { Recommendation } \\
\text { number }\end{array}$ & Recommendation statement and level \\
\hline $\mathbf{3 a}$ & $\begin{array}{l}\text { Clinicians should offer melatonin to children and adolescents with ASD if behavioral strategies have not been helpful and } \\
\text { contributing coexisting conditions and use of concomitant medications have been addressed (Level B). }\end{array}$ \\
\hline $\mathbf{3 b}$ & $\begin{array}{l}\text { Clinicians offering melatonin for sleep disturbance in children and adolescents with ASD should write a prescription for melatonin } \\
\text { or recommend using a high-purity pharmaceutical grade of melatonin when available (Level B). }\end{array}$ \\
\hline $\mathbf{3 c}$ & $\begin{array}{l}\text { Clinicians offering melatonin for sleep dysregulation in children and adolescents with ASD should start by initiating a low dose (1-3 } \\
\text { mg/d), 30-60 minutes before bedtime, and titrate to effect, not exceeding 10 mg/d (Level B). }\end{array}$ \\
\hline 3d & $\begin{array}{l}\text { Clinicians offering melatonin for sleep disturbance in children and adolescents with ASD should counsel children and adolescents } \\
\text { with ASD and sleep disturbance (as appropriate) and their parents regarding potential adverse events of melatonin use and the } \\
\text { lack of long-term safety data (Level B). }\end{array}$ \\
\hline
\end{tabular}

up to $10 \mathrm{mg}$ (modal dose $7 \mathrm{mg}$ ). ${ }^{31}$ In practice, variable concentrations of melatonin are found in OTC preparations, ${ }^{43}$ such that melatonin obtained by prescription is more representative of what was used in studies than OTC forms. When used as a hypnotic, melatonin is generally administered 30-60 minutes before bedtime. ${ }^{50}$ Because immediate-release melatonin has a short half-life (40 minutes), it is assumed that the immediaterelease formulations are more helpful for sleep-onset insomnia and controlled-release forms for sleep maintenance.

No study in the SR reported serious AEs. AEs reported with melatonin include morning drowsiness, increased enuresis, headache, dizziness, diarrhea, rash, and hypothermia. ${ }^{44-47} \mathrm{Mel}-$ atonin is currently used safely as neuroprotection in preterm infants, ${ }^{51}$ suggesting that it may also be safe in other pediatric populations, but long-term safety data are lacking for all pediatric populations. Possible long-term AEs are of particular concern given melatonin's ability to suppress the hypothalamic-gonadal axis and potentially initiate precocious puberty. ${ }^{52}$ Risk associated with melatonin use in ASD should be weighed against the harms of persistently disordered sleep for individuals with ASD and their families. It is axiomatic of good care that use of any behavioral or medical treatment be periodically reevaluated to ensure that there is continued benefit and no new AEs.

\section{Recommendation 4 rationale: CAM approaches}

Families of children and adolescents with ASD are often interested in CAM approaches. The SR identified that STS mattress technology possibly results in higher SE over 2 weeks but possibly fails to improve SOL, WASO, or TST. Weighted blankets possibly fail to improve SOL, SE, WASO, night awakenings, TST, and daytime behavior over 2 weeks. No highquality studies of other CAM approaches were identified. AEs were not described in the STS mattress study. The only AE in the weighted blanket study was a 2-day skin rash on one child that might have been blanket-related. Weighted blankets vary in approach to production; in the available study, weighted blankets were chosen to avoid extreme thickness and weighed $2.25 \mathrm{~kg}$ (small) or $4.5 \mathrm{~kg}$ (large) by using $3-\mathrm{mm}$ steel shot pellets embedded evenly throughout the blanket.

\section{Suggestions for future research}

There are few well-designed studies of sleep-related treatments in ASD. Optimal outcome measures (e.g., questionnaires, polysomnography, actigraphy) that balance tolerability and accuracy are undefined, as are clinically important differences for most measures. Melatonin has the strongest evidence for use. Given melatonin's ability to suppress the hypothalamicgonadal axis and potentially initiate precocious puberty, future directions should include the evaluation of long-term AEs with chronic melatonin use. Studies of individuals with ASD and concomitant mood disorders are also needed. The bidirectional relationship between poor sleep and mood disorders is welldocumented. Many people with ASD and mood disorders may

Table 4 Recommendation statements for care of children and adolescents with autism spectrum disorder (ASD) and sleep disturbance regarding complementary alternative medicine

\section{Recommendation} number

$4 a$

$4 b$

\section{Recommendation statement and level}

Clinicians should counsel children and adolescents with ASD and sleep disturbance (as appropriate) and their parents that there is currently no evidence to support the routine use of weighted blankets or specialized mattress technology for improving disrupted sleep (Level B). ${ }^{\text {a }}$

Although evidence of efficacy is lacking, clinicians should counsel children and adolescents with ASD and sleep disturbance (as appropriate) and their parents asking about weighted blankets that the reviewed trial reported no serious adverse events with blanket use and that blankets could be a reasonable nonpharmacologic approach to try for some individuals (Level B).

a Level B based on importance of outcomes, variation in preferences. 
also take medications that affect sleep. Finally, research tying the underlying neurobiology in early-life sleep disruption to behavior might help clinicians and researchers understand which treatments might work for which people with ASD.

\section{Disclaimer}

Practice guidelines, practice advisories, comprehensive systematic reviews, and other guidance published by the American Academy of Neurology (AAN) and its affiliates are assessments of current scientific and clinical information provided as an educational service. The information (1) should not be considered inclusive of all proper treatments, methods of care, or as a statement of the standard of care; (2) is not continually updated and may not reflect the most recent evidence (new evidence may emerge between the time information is developed and when it is published or read); (3) addresses only the question(s) specifically identified; (4) does not mandate any particular course of medical care; and (5) is not intended to substitute for the independent professional judgment of the treating provider, as the information does not account for individual variation among patients. In all cases, the selected course of action should be considered by the treating provider in the context of treating the individual patient. Use of the information is voluntary. AAN provides this information on an "as is" basis, and makes no warranty, expressed or implied, regarding the information. AAN specifically disclaims any warranties of merchantability or fitness for a particular use or purpose. AAN assumes no responsibility for any injury or damage to persons or property arising out of or related to any use of this information or for any errors or omissions. Drs. Buckley and Thurm provided scientific expertise. These recommendations in no way represent a position from the $\mathrm{Na}$ tional Institute of Mental Health or the NIH.

\section{Conflict of interest}

The American Academy of Neurology (AAN) is committed to producing independent, critical, and trustworthy clinical practice guidelines and evidence-based documents. Significant efforts are made to minimize the potential for conflicts of interest to influence the recommendations of this evidence-based document. Management and disclosure of document developer relationships is conducted in compliance with the 2011 AAN process manual section titled "Revealing conflicts of interest," which can be viewed at aan.com. ${ }^{24}$

\section{Author contributions}

Ashura Buckley: drafting/revising the manuscript, data acquisition, study concept or design, analysis or interpretation of data, accepts responsibility for conduct of research and final approval. Deborah G. Hirtz: drafting/revising the manuscript, data acquisition, study concept or design, analysis or interpretation of data, accepts responsibility for conduct of research and final approval. Maryam Oskoui: analysis or interpretation of data, accepts responsibility for conduct of research and final approval. Melissa J. Armstrong: drafting/ revising the manuscript, analysis or interpretation of data, accepts responsibility for conduct of research and final approval, statistical analysis. Anshu Batra: drafting/revising the manuscript, accepts responsibility for conduct of research and final approval. Carolyn Bridgemohan: drafting/revising the manuscript, data acquisition, analysis or interpretation of data, accepts responsibility for conduct of research and final approval, acquisition of data, study supervision, critical revision of the manuscript for important intellectual content. Daniel Coury: drafting/revising the manuscript, study concept or design, analysis or interpretation of data, accepts responsibility for conduct of research and final approval. Geraldine Dawson: drafting/revising the manuscript, analysis or interpretation of data, accepts responsibility for conduct of research and final approval. Diane Donley: drafting/revising the manuscript, accepts responsibility for conduct of research and final approval, study supervision. Robert Findling: drafting/revising the manuscript, analysis or interpretation of data, accepts responsibility for conduct of research and final approval. Thomas Gaughan: drafting/revising the manuscript, data acquisition, study concept or design, accepts responsibility for conduct of research and final approval, study supervision. David Gloss: drafting/revising the manuscript, data acquisition, analysis or interpretation of data, accepts responsibility for conduct of research and final approval. Gary Gronseth: study concept or design, analysis or interpretation of data, accepts responsibility for conduct of research and final approval, study supervision. Riley Kessler: analysis or interpretation of data, accepts responsibility for conduct of research and final approval. Shannon Ashley Merillat: drafting/revising the manuscript, data acquisition, study concept or design, accepts responsibility for conduct of research and final approval, study supervision. David J. Michelson: drafting/revising the manuscript, analysis or interpretation of data, accepts responsibility for conduct of research and final approval. Judith Owens: drafting/revising the manuscript, study concept or design, accepts responsibility for conduct of research and final approval. Tamara M. Pringsheim: drafting/revising the manuscript, data acquisition, study concept or design, analysis or interpretation of data, accepts responsibility for conduct of research and final approval. Linmarie Sikich: drafting/revising the manuscript, analysis or interpretation of data, accepts responsibility for conduct of research and final approval. Aubyn Stahmer: drafting/revising the manuscript, accepts responsibility for conduct of research and final approval. Audrey Thurm: drafting/revising the manuscript, accepts responsibility for conduct of research and final approval. Roberto Tuchman: drafting/revising the manuscript, accepts responsibility for conduct of research and final approval. Zachary Warren: drafting/revising the manuscript, study concept or design, analysis or interpretation of data, accepts responsibility for conduct of research and final approval. Amy Wetherby: drafting/revising the manuscript, accepts responsibility for conduct of research and final approval. Max Wiznitzer: drafting/revising the manuscript, analysis or interpretation of data, accepts responsibility for conduct 
of research and final approval. Stephen Ashwal: drafting/ revising the manuscript, accepts responsibility for conduct of research and final approval. Go to Neurology.org/ $\mathrm{N}$ for full disclosures.

\section{Acknowledgment}

The authors thank Beth Malow, MD, MS, for contributions and Julie Cox, MFA, for editorial assistance. C. Bridgemohan, who made substantial contributions to the development of this guideline, is deceased.

\section{Study funding}

This document was developed with financial support from the American Academy of Neurology (AAN). Authors who serve or served as AAN subcommittee members (D.H., M.O., D.D., D.M., S.A.) or as methodologists (M.J.A., D.G., G.G., T.P.) or as staff (S.M.) were reimbursed by the AAN for expenses related to travel to subcommittee meetings where drafts of the manuscript were reviewed.

\section{Disclosure}

A. Buckley serves on the editorial board for the journal Behavioral Sleep Medicine. D. Hirtz is on the executive boards of the Pediatric Epilepsy Research Foundation, the Cerebral Palsy Research Network, The CHILD-BRITE network (Canada), The North American Antiepileptic Drug Pregnancy Registry, and the TENDR group (Targeting Environmental Neurodevelopmental Risks), and has received funding for travel to meetings from those organizations. She is also on the Vermont State Concussion Task Force, The UVM Autism Collaborative, and the Vermont Interagency Committee on Chemical Management, with no funds received. M. Oskoui has received funding for travel to guideline subcommittee meetings from the American Academy of Neurology (AAN); serves as a paid evidence-based medicine methodologist for the AAN; has received research support from Fonds de recherche Sante du Québec, Canada Institute of Health Research, McGill University Research Institute, the SickKids Foundation, Cerebral Palsy Alliance Foundation, Kids Brain Health Network, and la Fondation du Grand défi Pierre Lavoie; has served on the data safety monitoring board for AveXis; has received financial compensation for consulting work for Biogen and Roche; and has received research support as site principal investigator for Ionis, Biogen, Roche, and Cytokinetics for clinical trials in spinal muscular atrophy. M. Armstrong serves on the Level of Evidence editorial board for Neurology ${ }^{\circledR}$ (not compensated financially), has received funding for travel to guideline subcommittee meetings from the AAN, and serves as a paid evidence-based medicine methodologist for the AAN. A. Batra reports no disclosures relevant to the manuscript. C. Bridgemohan is deceased; disclosures are not included for this author. D. Coury serves on an advisory board for Cognoa; receives research grant support from Neurim Pharmaceuticals and Stalicla SA; serves on a data safety monitoring committee for AMO Pharma; serves as coinvestigator for the National Center for Complementary and Integrative Health study Fatty Acid Supplementation in Children with ASD (Omega Heroes; ClinicalTrials.gov identifier
NCT03550209), examining an omega-3 supplement to treat autism spectrum disorder (ASD); serves on an advisory board for Quadrant Biosciences; and receives research grant support from Stemina Biomarker Discovery. G. Dawson is on the Scientific Advisory Boards of Janssen Research and Development, Akili, Inc., LabCorp, Inc., and Roche Pharmaceutical Company; a consultant for Apple, Inc., Gerson Lehrman Group, Guidepoint, Inc., and Axial Ventures; has received grant funding from Janssen Research and Development; is CEO of DASIO, LLC; has developed technology that has been licensed and G. Dawson and Duke University have benefited financially; and receives royalties from Guilford Press, Springer, and Oxford University Press. D. Donley has received funding for travel to guideline subcommittee meetings from the AAN, reviews child neurology cases for Physicians Review Organization of Michigan (PROM), an independent company related to the Michigan State Medical Society that performs independent reviews of hospitalizations at various Michigan facilities, and her husband, Bradley Evans, MD, reviews adult neurology PROM cases. Dr. Donley reads pediatric EEGs, and her husband reads adult EEGs, that are performed at Munson Medical Center. Dr. Donley's husband is principal investigator at the Northern Michigan Neurology site for multicenter clinical drug trials, phases 2-4, for multiple sclerosis (MS), Alzheimer disease, and Parkinson disease, and she serves as blinded rater for these trials, 2 of which were MS trials that Sanofi sponsored and for which patients were compensated for travel mileage. R. Findling receives or has received research support from Aevi, Akili, Albcobra, Allergan, Forest, Lundbeck, the NIH, Neurim, PCORI, Pfizer, Roche, Shire, Sunovion, Supernus Pharmaceuticals, Syneurx, and Validus; has served as a consultant for Acadia, Aevi, Akili, Alcobra, Allergan, Amerex, Arbor, Bracket, ePharmaSolutions, Genentech, Ironshore, KemPharm, Luminopia, Lundbeck, Merck, the NIH, Neurim, Noven, Nuvelution, Otsuka, Physicians Postgraduate Press, Receptor Life Sciences, Shire, Sunovion, Supernus Pharmaceuticals, Teva, Touchpoint, Tris, and Validus; has served on speakers bureaus for the American Academy of Child and Adolescent Psychiatry and Daiichi-Sankyo; and has received royalties from the American Psychiatric Press and Sage. T. Gaughan reports no disclosures relevant to the manuscript. D. Gloss has received funding for travel to guideline subcommittee meetings from the AAN, has served as a paid evidence-based medicine consultant for the AAN, and has served as an associate editor (risk of bias classification) for Neurology. G. Gronseth has received funding for travel to guideline subcommittee meetings from the AAN, has served as a paid evidence-based medicine consultant for the AAN, serves as an associate editor of Neurology and of Brain \& Life, and has received honoraria for presentations at the AAN annual meeting. R. Kessler, S. Merillat, and D. Michelson report no disclosures relevant to the manuscript. J. Owens serves as a consultant for Jazz Pharmaceuticals, TouchPoint, and Sleep Number; receives royalties from Wolters Kluwer and WebMD; has received funding for travel for presentations at meetings; receives compensation as Editor-in-Chief of Behavioral Sleep Medicine; and serves on the editorial boards of Sleep Medicine Reviews and Sleep Health. T. Pringsheim has received funding for travel to guideline subcommittee meetings 
from the AAN and has served as a paid evidence-based medicine methodologist for the AAN. L. Sikich has served on the advisory board (unpaid) for Neuren Pharmaceuticals; has participated in industry-funded trials as a site principal investigator or coinvestigator for Otsuka/Bristol-Myers Squibb, Sunovion, Roche, Janssen, and Curemark; has served as Duke Clinical Research Institute thought leader or medical monitor on trials conducted with KemPharm and Akili; has received research funding from the NIH as a principal investigator or project lead for studies examining treatment of comorbid ASD and attention-deficit/ hyperactivity disorder, long-term safety of antipsychotic use, biomarkers in ASD, oxytocin treatment in ASD, and treatment of antipsychotic medication-associated weight gain in children; serves on the Data Safety and Monitoring Board of the National Institute of Child Health and Human Development (NICHD) Rare Disease Consortium; and receives publishing royalties for Pediatric Psychopharmacology, 2nd edition. A. Stahmer serves as an editor for Autism: International Journal of Research and Practice and on the editorial board for the Journal of Early Intervention; has received funding for travel to scientific meetings and research support from the National Institute of Mental Health (NIMH), Health Resources and Services Administration (HRSA), and Institute of Education Sciences (IES); has received speaking honoraria; has received publishing royalties from Guilford Press; has received honoraria from Autism Speaks and NIMH for grant reviews; received payment to conduct training in behavioral interventions for ASD; dedicates $10 \%$ of clinical efforts to behavioral parent training; and has received research support from the NIMH, HRSA, and the IES. A. Thurm serves on the editorial boards of the Journal of Autism and Developmental Disorder and Journal of Developmental and Behavioral Pediatrics. R. Tuchman serves on the Autism Speaks Scientific Advisory Committee and expends $10 \%$ of his clinical efforts performing EEG and video EEG. Z. Warren serves on the editorial board for Autism: International Journal of Research and Practice and Journal of Autism and Developmental Disorders; has been compensated for service on scientific advisory and data safety and monitoring boards for Roche Pharmaceutical; received research support from Cognoa, SynapDx, and Stemina; expends $20 \%$ of his clinical efforts performing diagnostic assessments for children at risk for ASD; receives payment from the Adaptive Technology Consulting as an external consultant on an NIH NIMH Small Business Innovation Research grant; and has received grant support from the Agency for Healthcare Research and Quality, Autism Speaks, the Centers for Disease Control and Prevention, Department of Defense, HRSA, Maternal and Child Health Bureau, NIMH, the NICHD, National Science Foundation, and Simons Foundation. A. Wetherby serves on the editorial advisory board for the Journal of Autism and Developmental Disorders; performs grant review for the $\mathrm{NIH}$; receives publishing royalties from Brookes Publishing Company for Communication and Symbolic Behavior Scales and the SCERTS Model: A Comprehensive Educational Approach for Children with Autism Spectrum Disorders; and received financial support from the NIH NIMH, NIH NICHD, NIH National Institute on Deafness and Communication Disorders, the Centers for Disease Control and Prevention, and the US Department of Education. M. Wiznitzer serves on the editorial boards of Lancet Neurology and the Journal of Child Neurology; received honoraria as a speaker for AAN and American Academy of Pediatrics meetings; has given expert testimony for medical malpractice proceedings and the Vaccine Injury Compensation Program-Expert Witness for the US Department of Health and Human Services (written opinions and hearing testimony); and prepared an affidavit for a medical malpractice case. S. Ashwal has received funding for travel to guideline subcommittee meetings from the AAN; serves on the medical advisory board of the Tuberous Sclerosis Association; receives publishing royalties as coeditor of Pediatric Neurology: Principles and Practice, 6th edition; serves on the executive board of the Pediatric Epilepsy Research Foundation; and is a paid staff member at Loma Linda University School of Medicine, Department of Pediatrics. Go to Neurology.org/ $\mathrm{N}$ for full disclosures.

\section{Publication history}

Received by Neurology April 12, 2019. Accepted in final form December 9, 2019.

\section{References}

1. Richdale AL. Sleep problems in autism: prevalence, cause, and intervention. Dev Med Child Neurol 1999;41:60-66.

2. Reynolds AM, Malow BA. Sleep and autism spectrum disorders. Pediatr Clin North Am 2011;58:685-698.

3. Hodge D, Carollo TM, Lewin M, Hoffman CD, Sweeney DP. Sleep patterns in children with and without autism spectrum disorders: developmental comparisons. Res Dev Disabil 2014;35:1631-1638.

4. Delahaye J, Kovacs E, Sikora D, et al. The relationship between health-related quality of life and sleep problems in children with autism spectrum disorders. Res Autism Spectr Disord 2014;8:292-303.

5. Cohen S, Conduit R, Lockley SW, Rajaratnam SM, Cornish KM. The relationship between sleep and behavior in autism spectrum disorder (ASD): a review. J Neurodev Disord 2014;6:44.

6. Goldman SE, Richdale AL, Clemons T, Malow BA. Parental sleep concerns in autism spectrum disorders: variations from childhood to adolescence. J Autism Dev Disord 2012;42:531-538.

7. Robinson AM, Richdale AL. Sleep problems in children with an intellectual disability: parental perceptions of sleep problems, and views of treatment effectiveness. Child Care Health Dev 2004;30:139-150.

8. Park JH, An H, Jang ES, Chung S. The influence of personality and dysfunctional sleep-related cognitions on the severity of insomnia. Psychiatry Res 2012;197: 275-279.

9. Tudor ME, Hoffman CD, Sweeney DP. Children with autism: sleep problems and symptom severity. Focus Autism Other Dev Dis 2012;27:254-262.

10. Meltzer LJ. Brief report: sleep in parents of children with autism spectrum disorders. J Pediatr Psychol 2008;33:380-386.

11. Patzold LM, Richdale AL, Tonge BJ. An investigation into sleep characteristics of children with autism and Asperger's disorder. J Paediatr Child Health 1998;34: 528-533.

12. Gottlieb DJ, Vezina RM, Chase C, et al. Symptoms of sleep-disordered breathing in 5year-old children are associated with sleepiness and problem behaviors. Pediatrics 2003;112:870-877.

13. Schreck KA, Mulick JA, Smith AF. Sleep problems as possible predictors of intensified symptoms of autism. Res Dev Disabil 2004;25:57-66.

14. Schwebel DC, Brezausek CM. Nocturnal awakenings and pediatric injury risk. J Pediatr Psychol 2008;33:323-332.

15. Koulouglioti C, Cole R, Kitzman H. Inadequate sleep and unintentional injuries in young children. Public Health Nurs 2008;25:106-114.

16. Lumeng JC, Somashekar D, Appugliese D, Kaciroti N, Corwyn RF, Bradley RH. Shorter sleep duration is associated with increased risk for being overweight at ages 9 to 12 years. Pediatrics 2007;120:1020-1029.

17. Perez-Chada D, Perez-Lloret S, Videla AJ, et al. Sleep disordered breathing and daytime sleepiness are associated with poor academic performance in teenagers: a study using the Pediatric Daytime Sleepiness Scale (PDSS). Sleep 2007;30:1698-1703.

18. Fallone G, Acebo C, Seifer R, Carskadon MA. Experimental restriction of sleep opportunity in children: effects on teacher ratings. Sleep 2005;28:1561-1567.

19. Owens JA, Belon K, Moss P. Impact of delaying school start time on adolescent sleep, mood, and behavior. Arch Pediatr Adolesc Med 2010;164:608-614.

20. Carmassi C, Palagini L, Caruso D, et al. Systematic review of sleep disturbances and circadian sleep desynchronization in autism spectrum disorder: toward an integrative model of a self-reinforcing loop. Front Psychiatry 2019;10:366. 
21. American Academy of Sleep Medicine. Case Book of Sleep Medicine, 2nd ed. Darien, IL: American Academy of Sleep Medicine; 2015.

22. Bootzin RR, Stevens SJ. Adolescents, substance abuse, and the treatment of insomnia and daytime sleepiness. Clin Psychol Rev 2005;25:629-644.

23. Perfect MM, Elkins GR. Cognitive-behavioral therapy and hypnotic relaxation to treat sleep problems in an adolescent with diabetes. J Clin Psychol 2010;66:1205-1215.

24. American Academy of Neurology. Clinical Practice Guideline Process Manual. St. Paul, MN: American Academy of Neurology; 2011.

25. American Psychiatric Association. Diagnostic and Statistical Manual of Mental Disorders (5th ed., text rev.). Arlington, VA: American Psychiatric Publishing; 2013.

26. Owens JA, Spirito A, McGuinn M. The Children's Sleep Habits Questionnaire (CSHQ): psychometric properties of a survey instrument for school-aged children. Sleep 2000;23:1043-1051.

27. Einfeld SL, Tonge BJ. Manual for the Developmental Behaviour Checklist: Primary Carer Version (DBC-P) \& Teacher Version (DBC-T), 2nd ed. Clayton, Australia: Monash University Centre for Developmental Psychiatry and Psychology; 2002

28. Aman MG, Singh NN, Stewart AW, Field CJ. The aberrant behavior checklist: a behavior rating scale for the assessment of treatment effects. Am J Ment Defic 1985;89: $485-491$.

29. Cortesi F, Giannotti F, Sebastiani T, Panunzi S, Valente D. Controlled-release melatonin, singly and combined with cognitive behavioural therapy, for persistent insomnia in children with autism spectrum disorders: a randomized placebo-controlled trial. J Sleep Res 2012;21:700-709.

30. American Psychiatric Association. Diagnostic and Statistical Manual of Mental Disorders (4th ed., text rev.). Washington, DC: American Psychiatric Publishing; 2000.

31. Gringras P, Nir T, Breddy J, Frydman-Marom A, Findling RL. Efficacy and safety of pediatric prolonged-release melatonin for insomnia in children with autism spectrum disorder. J Am Acad Child Adolesc Psychiatry 2017;56:948-957.e944.

32. Wright B, Sims D, Smart S, et al. Melatonin versus placebo in children with autism spectrum conditions and severe sleep problems not amenable to behaviour management strategies: a randomised controlled crossover trial. J Autism Dev Disord 2011;41:175-184.

33. Adkins KW, Molloy C, Weiss SK, et al. Effects of a standardized pamphlet on insomnia in children with autism spectrum disorders. Pediatrics 2012;130(suppl 2):S139-S144.

34. Malow BA, Adkins KW, Reynolds A, et al. Parent-based sleep education for children with autism spectrum disorders. J Autism Dev Disord 2014;44:216-228.

35. Johnson CR, Turner KS, Foldes E, Brooks MM, Kronk R, Wiggs L. Behavioral parent training to address sleep disturbances in young children with autism spectrum disorder: a pilot trial. Sleep Med 2013;14:995-1004.

36. Gringras P, Green D, Wright B, et al. Weighted blankets and sleep in autistic children: a randomized controlled trial. Pediatrics 2014;134:298-306.
37. Frazier TW, Krishna J, Klingemier E, Beukemann M, Nawabit R, Ibrahim S. A randomized, crossover trial of a novel sound-to-sleep mattress technology in children with autism and sleep difficulties. J Clin Sleep Med 2017;13:95-104.

38. Medic G, Wille M, Hemels ME. Short- and long-term health consequences of sleep disruption. Nat Sci Sleep 2017;9:151-161.

39. Veatch OJ, Maxwell-Horn AC, Malow BA. Sleep in autism spectrum disorders. Curr Sleep Med Rep 2015;1:131-140.

40. Malow BA, Byars K, Johnson K, et al. A practice pathway for the identification, evaluation, and management of insomnia in children and adolescents with autism spectrum disorders. Pediatrics 2012;130(suppl 2):S106-S124.

41. Hartz I, Furu K, Bratlid T, Handal M, Skurtveit S. Hypnotic drug use among 0-17 year olds during 2004-2011: a nationwide prescription database study. Scand J Public Health 2012;40:704-711

42. Cerezo AB, Leal A, Alvarez-Fernandez MA, Hornedo-Ortega R, Troncoso AM, Garcia-Parrilla MC. Quality control and determination of melatonin in food sup plements. J Food Compost Anal 2016;45:80-86.

43. Erland LA, Saxena PK. Melatonin natural health products and supplements: presence of serotonin and significant variability of melatonin content. J Clin Sleep Med 2017; 13:275-281.

44. Bruni O, Alonso-Alconada D, Besag F, et al. Current role of melatonin in pediatric neurology: clinical recommendations. Eur J Paediatr Neurol 2015;19:122-133.

45. Hoebert M, van der Heijden KB, van Geijlswijk IM, Smits MG. Long-term follow-up of melatonin treatment in children with $\mathrm{ADHD}$ and chronic sleep onset insomnia. J Pineal Res 2009;47:1-7.

46. van Geijlswijk IM, Mol RH, Egberts TC, Smits MG. Evaluation of sleep, puberty and mental health in children with long-term melatonin treatment for chronic idiopathic childhood sleep onset insomnia. Psychopharmacology 2011;216:111-120.

47. van Geijlswijk IM, van der Heijden KB, Egberts AC, Korzilius HP, Smits MG. Dose finding of melatonin for chronic idiopathic childhood sleep onset insomnia: an RCT. Psychopharmacology 2010;212:379-391.

48. Shi L, Li N, Bo L, Xu Z. Melatonin and hypothalamic-pituitary-gonadal axis. Curr Med Chem 2013;20:2017-2031

49. Henderson K. Policies and practices used by states to serve children with autism spectrum disorders. J Disabil Pol Stud 2011;22:106-115.

50. Cummings C, Canadian Paediatric Society. Melatonin for the management of sleep disorders in children and adolescents. Paediatr Child Health 2012;17:331-336.

51. Biran V, Phan Duy A, Decobert F, Bednarek N, Alberti C, Baud O. Is melatonin ready to be used in preterm infants as a neuroprotectant? Dev Med Child Neurol 2014;56 717-723.

52. Kennaway DJ. Potential safety issues in the use of the hormone melatonin in paediatrics. J Paediatr Child Health 2015;51:584-589.

\section{Pre-order Annual Meeting On Demand and Save \$150+}

Save $\$ 150+$ when you pre-order 2020 Annual Meeting On Demand by May 1 . This comprehensive, CME-accredited digital library of presentations from the 2020 AAN Annual Meeting gives you ready access to 500 hours of content and syllabi from more than 200 top-tier programs-from the convenience of your home or office! Order yours now at AAN.com/view/20AMOD.

\section{Neurology ${ }^{\circledR}$ Online CME Program}

Earn CME while reading Neurology. This program is available only to online Neurology subscribers. Read the articles marked CME, go to Neurology.org, and click on CME. This will provide all of the information necessary to get started. The American Academy of Neurology (AAN) is accredited by the Accreditation Council for Continuing Medical Education (ACCME) to sponsor continuing medical education for physicians. Neurology is planned and produced in accordance with the ACCME Essentials. For more information, contact AAN Member Services at 800-879-1960. 


\section{Neurology}

Practice guideline: Treatment for insomnia and disrupted sleep behavior in children and adolescents with autism spectrum disorder: Report of the Guideline Development,

Dissemination, and Implementation Subcommittee of the American Academy of Neurology

Ashura Williams Buckley, Deborah Hirtz, Maryam Oskoui, et al. Neurology 2020;94;392-404 Published Online before print February 12, 2020

DOI 10.1212/WNL.0000000000009033

This information is current as of February 12, 2020

Updated Information \& Services

References

Subspecialty Collections

Permissions \& Licensing

Reprints including high resolution figures, can be found at: http://n.neurology.org/content/94/9/392.full

This article cites 47 articles, 0 of which you can access for free at: http://n.neurology.org/content/94/9/392.full\#ref-list-1

This article, along with others on similar topics, appears in the following collection(s):

All Psychiatric disorders

http://n.neurology.org/cgi/collection/all_psychiatric_disorders All Sleep Disorders

http://n.neurology.org/cgi/collection/all_sleep_disorders

Autism

http://n.neurology.org/cgi/collection/autism

Developmental disorders

http://n.neurology.org/cgi/collection/developmental_disorders

Information about reproducing this article in parts (figures,tables) or in its entirety can be found online at:

http://www.neurology.org/about/about_the_journal\#permissions

Information about ordering reprints can be found online:

http://n.neurology.org/subscribers/advertise

Neurology ${ }^{\circledR}$ is the official journal of the American Academy of Neurology. Published continuously since 1951, it is now a weekly with 48 issues per year. Copyright () 2020 American Academy of Neurology. All rights reserved. Print ISSN: 0028-3878. Online ISSN: 1526-632X.

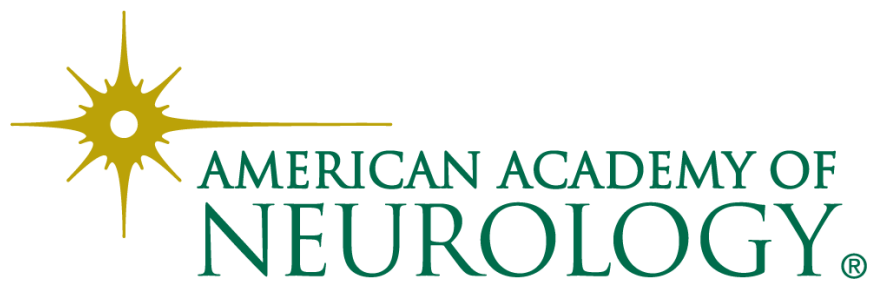

